\title{
Discogenic pain: Who cares?
}

\author{
José Pedro Lavrador*, Nuno Simas, Edson Oliveira, Joaquim Cruz Teixeira, Diogo Simão, \\ Sérgio Livraghi
}

Neurosurgical Department, Hospital Santa Maria, Lisbon, Portugal; ${ }^{*}$ Corresponding Author: jose.pedro.lavrador@gmail.com

Received 21 August 2013; revised 28 September 2013; accepted 12 October 2013

Copyright (c) 2013 José Pedro Lavrador et al. This is an open access article distributed under the Creative Commons Attribution License, which permits unrestricted use, distribution, and reproduction in any medium, provided the original work is properly cited.

\begin{abstract}
Chronic low back pain has a huge impact on daily living and a negative economic and professional effect. It is a matter of debate and concern for all health professionals involved, particularly spine surgeons. Recent discoveries on the innervation and biochemical properties of the intervertebral disc clarify the role of this structure as a possible cause of chronic low back pain. However, multiple causes may be present in the same patient making the diagnosis a challenging process. Discogenic pain is defined as a chronic low back pain induced by a degenerative disc disease. There are no specific characteristics of discogenic pain, although it has a higher incidence in younger age, it is usually localized medially in the back, worsens with axial loading and improves with recumbence. In the last decades we have assisted the emergence of multiple treatment techniques. However, neither the conservative treatment nor the interventional management has strong evidence in treating discogenic pain. Randomized control clinical trials are sought to improve patient outcome. Meanwhile, we believe each patient should be approached on an individual base. Discogenic pain: we care.
\end{abstract}

Keywords: Discogenic Pain; Low Back Pain; Intervertebral Disc

\section{INTRODUCTION}

Low back pain (LBP) became one of the leading problems in public health systems in the western world during the second half of the 20th century [1]. Most people will experience back pain at some point in their lives. It is estimated that an individual has an $80 \%$ probability of having low back pain at some period during his lifetime
[2]. In younger than 45 years, it has become the most common reason of limited activity. The treatment expense for low back pain in USA is higher than $\$ 100$ billion each year [3]. One study in the UK estimated that in 1998, direct health-care costs associated with back pain were approximately $£ 1.6$ billion, but the total costs related to loss of productivity were closer to $£ 11$ billion. [4].

Since early times low back pain with radicular leg pain has been described by many known physicians as Hippocrates, Schmorl and Dandy. However, the association between the disc disease and radicular leg pain was only clearly established by Mixter and Barr in 1934. Whereas lower-extremity radicular pain is well accepted as a symptom of lumbar disc disease-herniated disc with radicular compression, the association between a degenerated disc and non-radicular back pain remains more controversial. The concept of discogenic pain has emerged as a chronic low back pain induced by a degenerative disc disease by itself. Opponents of the discogenic pain have argued that there are no pain receptors within the intervertebral disc, therefore, discogenic pain cannot occur. Arguments for its existence are supported by both empirical clinical data and neuroanatomical research. In this article, the authors will review the embryological and anatomical aspects of intervertebral disc, its aging process, biomolecular basis as well as the clinical, imagiological and treatment features of discogenic pain.

From a global perspective, discogenic pain is a public health issue, especially among young adults, and should be a concern for all health professionals involved.

\section{INTERVERTEBRAL DISC: EMBRYOLOGY AND ANATOMY}

The intervertebral disc (IVD) is the main joint between two consecutive vertebrae in the vertebral column. [5].

Through embryological development, the intervertebral discs mature during the resegmentation of the axial 
organs. This occurs after the disintegration of the sclerotome when some cells migrate ventrally to the notochord forming a homogenous tissue around it [6]. The future vertebra starts to arise during the second month in the form of two small cartilage masses which are seen in the membranous vertebral column [7]. Part of the notochord is preserved as a gelatinous nucleus and the cell-poor material situated between the discs is transformed into hyaline cartilage [6].

The IVD is then formed and consists of three different structures: a gelatinous core called nucleus pulposus (NP), an outer ring of fibrous tissue called annulus fibrosus (AF) and two vertebral endplates of hyaline cartilage that cover the upper and lower surface of both NP and AF [5]. The IVD along with the facet joints provide support and stability by limiting the movement of the spine in all directions [8,9]. The IVD along with two adjacent vertebrae and all the ligaments between them constitute the spinal functional unit, defined as the smallest physiological motion unit of the spine to exhibit biomechanical characteristics similar to those of the entire spine.

The innervation of the IVD has been extensively studied. However, the available data has been obtained from experimentation in rats [5]. The normal IVD is poorly innervated, supplied only by sensory and sympathetic perivascular nerve fibers.

Most studies demonstrated that the IVD nerve fibers are found mostly in the periphery of the AF [5,10,11]. Sensory fibers are mostly nociceptive, located in the posterior outer layers of the AF and in the central portion of the vertebral endplates. Proprioceptive fibers can also be found in a lesser extent [8]. This innervation is accomplished by branches of the sinuvertebral nerve (capable of nociception) and branches of the paravertebral sympathetic trunks [5]. In IVD degeneration the number of nerve fibers increase which has been associated with discogenic pain $[5,12]$.

\section{AGING OF THE VERTEBRAL DISC}

It is well known the IVD undergoes structural changes from birth to old age. Disc degeneration is part of the aging process that affects not only the discs but other spinal structures leading to a deterioration of their function. However there are no clear boundaries between physiological aging and pathological degeneration.

Disc aging begins in the first 2 decades of life, reaches a steady-state during the third and fourth, and re-starts from the fifth to seventh.

The NP grows quickly during infancy. In this period it consists of clumps and strands of notochordal cells in a plentiful mucoid matrix [13]. The NP suffers considerable changes in the first years of life. During this period notochordal cells disappeared and the NP undergoes a gradual transformation, losing its gelatinous appearance and its translucency and turning into a soft, relatively acellular fibrocartilage [14].

The appearance of the adult disc nucleus with increasing age suffers several changes. The NP becomes less hydrated and more collagenous. It changes color, changing from white to yellow-brown through the accumulation of products of non-enzymatic glycosylation. These can also form cross-links between polypeptide chains and may alter the tissue's mechanical properties, reducing flexibility [15]. With age, the boundary between NP and AF becomes increasingly blurred and the annular rings thicken and appear more disorganized [16]. Later in life, tears and fissures emerge in the endplate; NP and AF almost vanish being replaced by disorganized scar or granulation tissue $[17,18]$.

There are several proposed risk factors involved in disc aging and degeneration. The reduction of disc cell nutrition is probably the most relevant factor. Cell culture studies demonstrate that synthesis of matrix is drastically reduced when oxygen concentration falls below 5\% or the $\mathrm{pH}$ is below 6.8 [19]. The mechanism leading to this loss of nutrition is still under investigation. Atherosclerosis is associated with increased degeneration [20,21]. Lack of physical activity may also have a negative impact on disc nutrition [22]. Studies in rats have shown a direct link between smoking and disc degeneration $[23,24]$. Although these risks factors have been identified, the exact mechanisms by which they promote disc changes are steel unclear.

Direct mechanical damage can be associated with degenerative progression and clinically significant LBP. This hypothesis is supported by experimental animal models [25-27] and epidemiological data, linking heavy lifting, intense physical work, and obesity with increaseing rates of LBP [28-30]. Supra-physiologic movements like bending, rotation, and compression can lead to structural defects associated with degeneration of the IVD [31]. A recent study has also shown that intense physical stress can induce a catabolic response characterized by increasing protease gene and protein expression/activity [32].

\section{BIOMOLECULAR ASPECTS OF IVD DEGENERATION}

The IVD is a dynamic structure and its matrix is in continuous turnover. This process may be divided in 3 different phases. The first phase-growth-is characterized by type II collagen and aggrecan synthesis. These components are responsible for the viscoelastic properties of the juvenile disc. The second phase-maturation -is defined by reduction of both these components. The third phase-degeneration and fibrosis-begins when type II collagen is denaturized and type I collagen syn- 
thesis is increased with no change in the aggrecan levels [33]. During this process, the total amount of elastin and the extracellular matrix degeneration products increase along with the decreasing of enzyme inhibitors [34,35]. As a consequence, the IVD becomes less flexible (Figure 1).

This collagen-proteoglycan imbalance is produced by aggrecanases, matrix metalloproteinase (MMP) and ADAMTS (a desintegrin and metalloproteinase with thrombospondin motifs) families. These enzymes are synthetized by IVD cells which are under the direct influence of diverse growth factors (namely insulin-like growth factor I (IGF-I), basic fibroblast growth factor (bFGF), platelet-derived growth factor (PDGF), transforming growth factor- $\beta$ (TGF- $\beta$ )), some bone morphogenic proteins (BMPs), and the cytokines interleukin-1 (IL-1) and IL-6, and tumor necrosis factor- $\alpha$ (TNF- $\alpha$ ) [36-38]. An acute inflammatory insult is thought to be responsible for the increase of catabolic/anabolic ratio. Furthermore, it is believed that the degenerative debris of IVD catabolism may increase this process, reducing the IVD proteoglycan and water content $[33,39]$.

The degenerative disc disease has a genetic predisposition which may account for $74 \%$ of inter-individual variability [40]. Many genes have been studied, including the vitamin $\mathrm{D}$ receptor (VDR on chromosome 12q13.11), alleles for collagen type IX, aggrecan and MMP-3 [41]. Vitamin D seems to have an important role in the proteoglycan synthesis and it has been identified two VDR restriction fragment length polymorphisms (Taq I and Fok I) related to disc degeneration on MRI [42]. The polymorphism characterized by tandem repeats of aggrecan gene (AGC1 on chromosome 15q26.1) has been recently enrolled in disc degeneration [43]. The collagen type IX genes for the $\alpha 2$ subunit (COL9A2 on chromosome 1p33-p33) and $\alpha 3$ subunit (COL9A3 on chromosome 20q13.3) and its polymorphisms (Trp2 and Trp3) have also been studied [44]. An altered aggrecan and collagen type IX function may account for biomechanical disc degeneration.

A great amount of biomarkers are on the line to enlighten disc degeneration phenomenon.

\section{DISCOGENIC PAIN MECHANISMS}

Discogenic pain is build up by a complex interaction
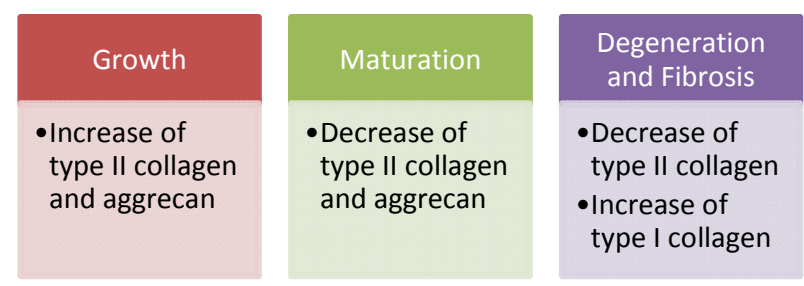

Figure 1. Biomolecular IVD evolution. of pro-inflammatory cytokines-mainly Tumor Necrosis Factor $\alpha$ (TNF- $\alpha)$, IL-1 $\beta$ and IL-8 [45] —and neurotrophins (NT) -Nerve Growth Factor (NGF), Brain-derived Growth Factor (BDGF), NT-E and NT-4/5 [46] -in the intervertebral body [5]. NT activates two different type of receptors: Trk-TrkA, TrkB and TrkC, and low-affinity $\mathrm{p} 75^{\mathrm{NTR}}$ [47].

Inflammation, whether induced by trauma or other insults, is the main trigger of this complex network. The above mentioned cytokines are released in the IVD during the acute inflammatory process. They will act on mast cells and macrophages receptors in order to increase the NGF and Substance P (SP) levels [48]. Two events will take place: a local positive feed-back effectNGF and SP increase their own concentration through mast cells and macrophages stimulation-and a retrograde peptide transport of NGF to dorsal root ganglia (DRG) which increases SP, BDNF and Calcitonin Gene Related Peptide (CGRP) by TrkA-expressing neurons $[5,49]$. These neurochemical changes in DRG promote an increase in the synaptic transmission in lamina I and II of the respective dorsal horn of spinal cord modulating the central pain pathways [50]. It also stimulates the ingrowth of nociceptive nerve fibers into the intervertebral body in association with aggrecan breakdown products. [51]. These last nerve fibers will deliver SP and NGF by anterograde transmission to the intervertebral body, enhancing the cycle. This complex neurochemical architecture is a solid platform through which discogenic pain can perpetuate (Figure 2).

\section{DIAGNOSING DISCOGENIC PAIN}

An accurate diagnosis is critical for a successful treatment of discogenic pain. Similarly to other spine degenerative disorders, the lumbar segment is the most affected by discogenic pain.

Facet joint degeneration, spinal instability, sacroiliac joint pathology, compressive syndromes, lumbar stenosis and psychological factors are other known causes for LBP that must be taken in consideration. In addition,

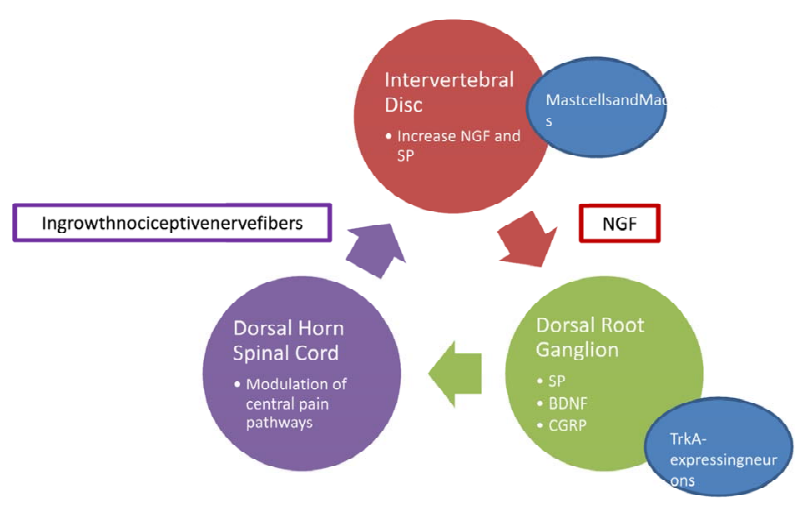

Figure 2. Discogenic pain mechanisms. 
multiple causes may be present in the same patient turning the diagnosis into a more challenging process.

There are no specific characteristics that clearly confirm or refute the diagnosis of discogenic pain. Usually it is a persistent and medially localized back pain, which can also be referred to the groin and/or leg. It worsens with axial loading and improves with recumbence.

In a retrospective study [52], younger age was a predictive factor of discogenic origin.

There are no pathognomonic signs of discogenic pain on physical examination. However some authors consider that biphasic straightening from flexion and pain exacerbation with pressure on the spinal process, are suggestive of discogenic pain.

Concerning the paucity of clinical and physical examination features, imaging is essential in the diagnosis of discogenic pain.

\section{IMAGING THE INTERVERTEBRAL DISC}

Imaging modalities, particularly Magnetic resonance (MR), can identify degenerative changes in IVD. However, its presence is not always associated with patient symptoms. In fact, there is a high prevalence of degenerative disc disease findings in asymptomatic persons [54]. MR is the most appropriate modality for evaluation of degenerative disc disease [8,55]. It has a sensitivity ranging from $60 \%$ to $100 \%$ and specificity of $43 \%$ to 97\% [55]. However, its predictive and prognostic information remains unclear [56]. Early disc degeneration appears in MR images with a diminished T2 signal intensity without evidence of disc collapse or herniation. This pattern is referred as "dehydrated", “desiccated" or "black" disc (Figure 3).

Dehydrated discs are associated with radial tears of the AF although MR frequently fails to show it [59]. Pfirrman et al. [60] developed a 5-grading scale to classify disc degeneration (Table 1).

Modic changes represent areas of abnormal signal in the vertebral endplate and subchondral bone marrow. They occur in $19 \%$ to $59 \%$ of patients with chronic LBP and are divided in three categories. Type 1 changes are hypointense on T1-weighted imaging (T1WI) and hyperintense on T2-weighted imaging (T2WI) and represent bone marrow edema and inflammation. Type 2 changes are hyperintense on T1WI and isointense or slightly hyperintense on T2WI and are associated with fatty infiltration after the acute inflammation. Type 3 changes are described as hypointense on both T1WI and T2WI and are thought to represent subchondral bone sclerosis [61]. Kuisma et al. suggested that Modic changes occurring at L5-S1 level, type 1 changes and extensive expression of Modic changes are more closely associated with pain [62]. Type 3 changes are not related

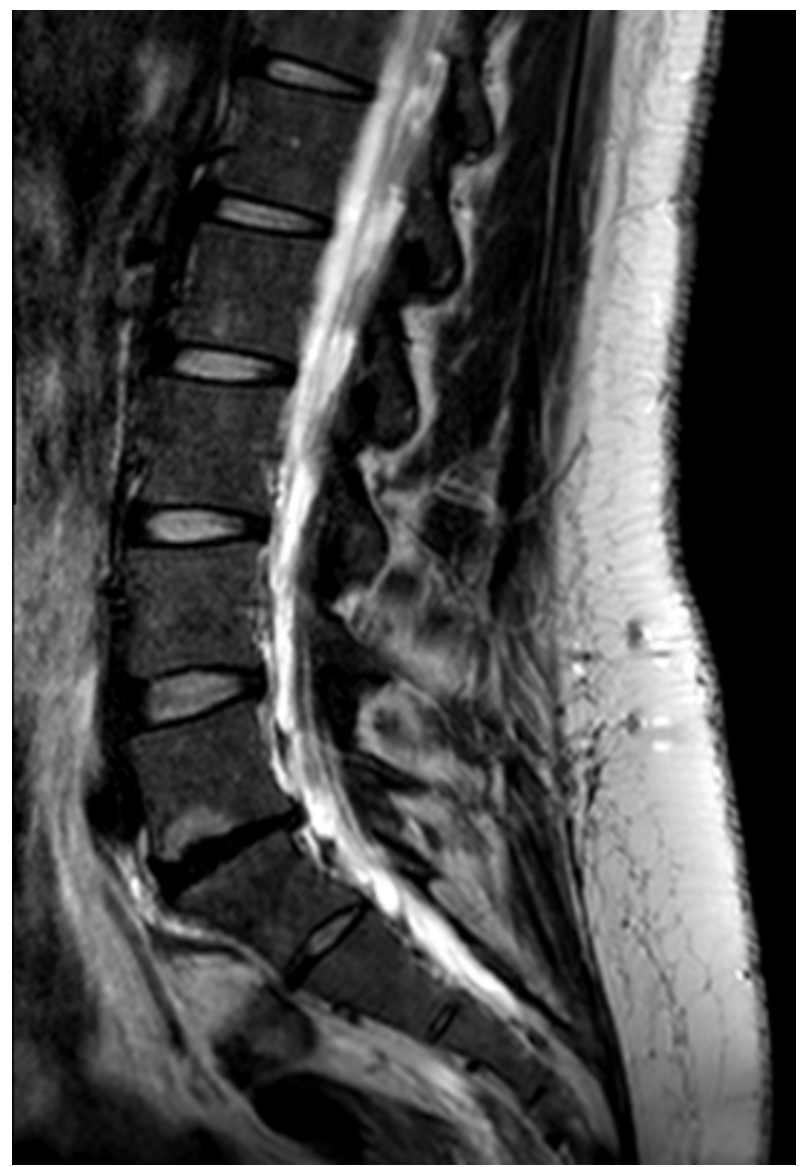

Figure 3. T2-weighted MR showing anL5-S1 black disc in a 30-year patient with LBP.

Table 1. Pffirman classification of disc degeneration.

\begin{tabular}{cccc}
\hline Grade & Structure & $\begin{array}{c}\text { Distinction of } \\
\text { Nucleus and Anulus }\end{array}$ & Signal Intensity \\
\hline I & Homogeneous, bright white & Clear & Hyperintense, isointense to CSF \\
II & Inhomogeneous with or without horizontal bands & Clear & Hyperintense, isointense to CSF \\
III & Inhomogeneous gray & Unclear & Intermediate \\
IV & Inhomogeneous gray to black & Lost & Intermediate to hypointense \\
V & Inhomogeneous black & Lost & Normal to moderately decreased \\
\hline
\end{tabular}


to pain [58]. The prevalence of Modic changes is variable but type 2 is generally more common than type 1 [63].

High-intensity zone lesions (HIZs) appear as high intensity signal within the posterior AF in T2-weighted MR images. They represent large radial or circumferential fissures [58]. HIZs are not a sign of back pain as they can be present in asymptomatic individuals. However, in a patient with back pain they strongly implicate the affected disc as the source of the pain [58].

MRI may identify a degenerative disc and an annular tear, but the evidence of disc degeneration does not necessarily correlate to the presence or severity of low back symptoms. In asymptomatic subjects, older than 50 years, $90 \%$ to $100 \%$ will have evidence of disc degeneration on MRI and Modic changes are evident in $20 \%$ of people without symptoms [65]. On the contrary, there are probably some patients with discogenic pain and innocent MR.

Provocation discography is the only available method that correlates the morphologic abnormalities with clinically observed pain. Kallewaard, J.W., et al. consider provocative discography the gold standard for diagnosis of discogenic pain [56]. This procedure consists in injecting a contrast agent in the NP of the target disc in order to test its sensitivity to gradually increasing pressures. The diagnostic criteria for IVD disease established by the International Association for the Study of Pain (IASP) are occurrence of a concordant pain response during discography, internal annular disruption shown by CT after discography and at least one adjacent disc without concordant pain. Nevertheless, its predictive value has been repeatedly questioned, mainly as a result of reported false positive rates [8]. Physicians must be aware of exaggerated responses to disc stimulation due to other factors, as psychometric variables or high contrast infusion rates [58]. In addition it is an invasive procedure and it implies the injection of an adjacent normal disc to confirm a positive response. Therefore this diagnostic modality should be reserved for patients with presumed discogenic LBP who may be candidates for surgical treatment [57] due to its invasive nature and poor evidence for its sensitivity, specificity, and predictive value.

Annular tears or fissures are avulsions in the AF fibers and can either involve the fibers themselves or the insertions on the adjacent endplates [63]. Based on CT-Discography, Sachs et al. developed the "Dallas Discogram Scale” of disc degeneration [64]. Grade 0 represents a disc in which the contrast remains in the NP. From Grade 1 to Grade 3, the contrast agent extends to the innermost, middle and outermost sections, respectively, of the AF. In Grade 4, fissures have expanded into an arc-shaped tear, outside of or in the innermost of the annulus. Grade 0 and 1 are almost never painful. On the other hand, more than $75 \%$ of the Grade 3 discographies are accompanied with the exact reproduction of concordant pain [8].

As exposed, there is not a consistent overlapping among discogenic pain, MR degenerative disc changes and positive discography findings (Figure 4).

\section{TREATING DISCOGENIC PAIN}

The socioeconomical impact of discal pathology has led to an expanding array of tests and treatments, including percutaneous and surgical procedures, implantable devices, and medications. However, innovation has often outpaced clinical science, leaving uncertainty about the efficacy of many novel treatments. Clinical benefits and therapeutic risks must be considered when dealing with clinical problem.

The conservative treatment with non-steroid anti-inflammatories and weak opioids may be administered for a limited period of time (3 months at most). Regarding the guidelines concerning the physical exercise, no evidence support bed rest when comparing with active exercise [66,67].

A huge amount of percutaneous techniques has been proposed for discogenic pain treatment. The intradiscal corticosteroid injections have been reported in patients with Modic Type-1 changes regarding their anti-inflammatory effect [68]. The intradiscal eletrothermal therapy consists of percutaneous insertion of a thermocoil into the IVD [69]. The bi-acuplasty delivers a radiofrequency (RF) current between two straight probes with preservation of the AF structure. The proposed action mechanisms are the denervation of local nociceptors or improving the AF stability throughout collagen structure changes [70]. The intradiscal radiofrequency thermocoagulation consists of RF deliver in the IVD center, decreasing the IVD pressure. Otherwise, the ramus communicans block act on the nociceptive pathway decreasing the IVD innervation and its surrounding structures. Ozone discolysis consists of injecting an $\mathrm{O}_{3}$ and $\mathrm{O}_{2}$ mixture intradiscally as well epidurally. As a result, an oxidative dehydration takes place in the NP as well as

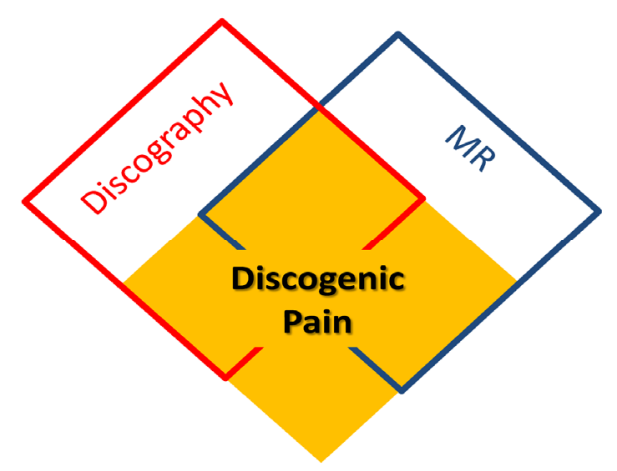

Figure 4. Diagnosing discogenic pain: a challenging process. 
an increase in the endogenous anti-inflammatory response due to oxidative stress which upregulates the intracellular antioxidant scavenger system [8]. Health care providers should be aware that neither of these percutaneous techniques has a strong level of recommendation in the treatment of discogenic pain.

Surgical treatment is also an option in the management of discogenic LBP. The surgical alternatives are lumbar fusion or total disc replacement.

Lumbar fusion lies on noninstrumented posterolateral fusion, instrumented posterolateral fusion or interbody graft with/without instrumented posterolateral fusion. In published studies using one of these techniques there has not been a consistent correlation between the fusion status and the patient's clinical outcome, but the addition of an interbody graft seems to have better results [71].

Total disc replacement or disc arthroplasty was developed in the attempt to avoid lumbar fusion drawnbacks such as pseudoarthrosis, degeneration of adjacent segments and mobility limitations. For now there is no evidence that this procedure show better outcomes than lumbar fusion [71].

The authors believe each patient should be approached on an individual base. We tend to prefer a conservative management and lifestyle adjustment, limiting axial loading activities and stimulating low stress aerobic exercises and those that minimally stress the back, including bicycling, walking and swimming. We do not propose percutaneous techniques regarding the lack of strong evidence supporting their use. In refractory cases, particularly in young and motivated patients, a surgical approach is sometimes proposed. In our experience and using this approach, the number of patients submitted to surgical treatment is minimal. Randomized control clinical trials are sought to improve our ability to take appropriate decisions and patient outcome.

\section{OVERVIEW}

Interest on discogenic pain has increased in health professionals all over the world. Chronic LBP has a huge impact on daily living and a strong negative economic and professional effect. The scientific community is increasing its knowledge regarding the mechanisms and treatment of discogenic pain. Nevertheless, this is a problem poorly understood, which explains the lack of good quality evidence treatment and should stimulate our effort in understanding its causes.

\section{REFERENCES}

[1] Balagué, F., Mannion, A.F., Pellisé, F. and Cedraschi, C. (2012) Non-specific low back pain. Lancet, 379, 482-491. http://dx.doi.org/10.1016/S0140-6736(11)60610-7

[2] Andersson, G.B. (1999) Epidemiological features of chro- nic low back pain. Lancet, 354, 581-585. http://dx.doi.org/10.1016/S0140-6736(99)01312-4

[3] Dagenais, S., Caro, J. and Haldeman, S. (2008) A systematic review of low back pain cost of illness studies in the United States and internationally. The Spine Journal, 8, 8-20. http://dx.doi.org/10.1016/j.spinee.2007.10.005

[4] Maniadakis, N. and Gray, A. (2000) The economic burden of back pain in the UK. Pain, 84, 95-103. http://dx.doi.org/10.1016/S0304-3959(99)00187-6

[5] Garcia-Cosamaló, J., Valle, M., Calavia, M., GarcĺaSuárez, O., López-Muñiz, A., Otero, J. and Veja, J. (2010) Intervertebral disc, sensory nerves and neurotrophins: Who is who in discogenic pain? Journal of Anatomy, 217, $1-15$.

[6] Ulrich, D. (1995) Color atlas of embryology: General embryology—Resegmentation of axial organs. Thieme.

[7] Pickering, P. and Robert, H. (1974) Gray’s anatomy: Embryology. Courage Books, 1149-1214.

[8] Kallewaard, J.W., Terheggen, M.A., Groen, G.J., Sluijter, M.E., Derby, R., Kapural, L., Mekhail, N. and van Kleef, M. (2010) Discogenic low back pain. Pain Practice, 10, 560-579. http://dx.doi.org/10.1111/j.1533-2500.2010.00408.x

[9] Cohen, S.P., Larkin, T.M., Barna, S.A., Palmer, W.E., Hecht, A.C. and Stojanovic, M.P. (2005) Lumbar discography: A comprehensive review of outcome studies, diagnostic accuracy, and principles. Regional Anesthesia and Pain Medicine, 30, 163-183.

http://dx.doi.org/10.1016/j.rapm.2004.10.006

[10] Edgar, M.A. (2007) The nerve supply of the lumbar intervertebral disc. The Bone \& Joint Journal, 89, 11351139. http://dx.doi.org/10.1302/0301-620X.89B9.18939

[11] Raj, P.P. (2008) Intervertebral disc: Anatomy-physiologypathophysiology-treatment. Pain Practice, 8, 18-44. http://dx.doi.org/10.1111/j.1533-2500.2007.00171.x

[12] Johnson, W.E., Patterson, A.M., Eisenstein, S.M. and Roberts, S. (2007) The presence of pleiotrophin in the human intervertebral disc is associated with increased vascularization: An immunohistologic study. Spine (Phila Pa 1976), 32, 1295-1302.

[13] Taylor, J.R. (1975) Growth of human intervertebral discs and vertebral bodies. Journal of Anatomy, 120, 49-68.

[14] Urgan, J.P.G., Roberts, S. and Ralphs, J.R. (2000) The nucleus of the intervertebral disc from development to degeneration. Integrative and Comparative Biology: Oxford Journals, 40, 53-61.

[15] Hormel, S.E. and Eyre, D.R. (1991) Collagen in the ageing human intervertebral disc: An increase in covalently bound fluorophores and chromophores. Biochimica et Biophysica Acta (BBA)—Protein Structure and Molecular Enzymology, 1078, 243-250.

[16] Coventry, M.B., Ghormley, R.K. and Kernohan J.W. (1945) The intervertebral disc: Its microscopic anatomy and pathology; anatomy, development and physiology. The Journal of Bone \& Joint Surgery, 27, 105-112.

[17] Thompson, J.P., Pearce, R.H., Schechter, M.T., Adams, M.E., Tsang, I.K.Y. and Bishop, P.B. (1990) Preliminary 
evaluation of a scheme for grading the gross morphology of the human intervertebral disc. Spine, 15, 411-415.

[18] Vernon-Roberts, B. (1992) Age related and degenerative pathology of the intervertebral discs and apophyseal joints. In: Jayson, M.I.V., Ed., The Lumbar Spine and Back Pain, Churchill Livingstone, London, 17-41.

[19] Ishihara, H. and Urban, J.P., (1999) Effects of low oxygen concentrations and metabolic inhibitors on proteoglycan and protein synthesis rates in the intervertebral disc. Journal of Orthopaedic Research, 17, 829-835. http://dx.doi.org/10.1002/jor.1100170607

[20] Kauppila, L.I., McAlindon, T., Evans, S., Wilson, P.W., Kiel, D. and Felson, D.T. (1997) Disc degeneration/back pain and calcification of the abdominal aorta. A 25-year follow-up study in Framingham. Spine, 22, 1642-1647. http://dx.doi.org/10.1097/00007632-199707150-00023

[21] Kauppila, L.I. (1997) Prevalence of stenotic changes in arteries supplying the lumbar spine. A postmortem angiographic study on 140 subjects. Annals of the Rheumatic Diseases, 56, 591-595. http://dx.doi.org/10.1136/ard.56.10.591

[22] Holm, S. and Nachemson, A. (1983) Variations in the nutrition of the canine intervertebral disc induced by motion. Spine, 8, 866-874. http://dx.doi.org/10.1097/00007632-198311000-00009

[23] Akmal, M., Kesani, A., Anand, B., Singh, A., Wiseman, M. and Goodship, A. (2004) Effect of nicotine on spinal disc cells: A cellular mechanism for disc degeneration. Spine, 29, 568-575. http://dx.doi.org/10.1097/01.BRS.0000101422.36419.D8

[24] Oda, H., Matsuzaki, H., Tokuhashi, Y., Wakabayashi, K., Uematsu, Y. and Iwahashi, M. (2004) Degeneration of intervertebral discs due to smoking: Experimental assessment in a rat-smoking model. Journal of Orthopaedic Science, 9, 135-141.

http://dx.doi.org/10.1007/s00776-003-0759-y

[25] Cassinelli, E.H., Hall, R.A. and Kang, J.D. (2001) Biochemistry of intervertebral disc degeneration and the potential for gene therapy applications. The Spine Journal, 1, 205-214.

http://dx.doi.org/10.1016/S1529-9430(01)00021-3

[26] Kroeber, M.W., Unglaub, F., Wang, H., Schmid, C., Thomsen, M., Nerlich, A. and Richter, W. (2002) New in vivo animal model to create intervertebral disc degeneration and to investigate the effects of therapeutic strategies to stimulate disc regeneration. Spine, 27, 2684-2690. http://dx.doi.org/10.1097/00007632-200212010-00007

[27] Rousseau, M.A., Ulrich, J.A., Bass, E.C., Rodriguez, A.G., Liu, J.J. and Lotz, J.C.(2007) Stab incision for inducing intervertebral disc degeneration in the rat. Spine, 32, 1724.

http://dx.doi.org/10.1097/01.brs.0000251013.07656.45

[28] Boos, N., Semmer, N., Elfering, A., Schade, V., Gal, I., Zanetti, M., Kissling, R., Buchegger, N., Hodler, J. and Main, C.J. (2000) Natural history of individuals with asymptomatic disc abnormalities in magnetic resonance imaging: Predictors of low back pain-related medical consultation and work incapacity. Spine, 25, 1484-1492. http://dx.doi.org/10.1097/00007632-200006150-00006
[29] Deyo, R.A. and Bass, J.E. (1989) Lifestyle and low-back pain. The influence of smoking and obesity. Spine, 14, 501-506. http://dx.doi.org/10.1097/00007632-198905000-00005

[30] Heliovaara, M. (1989) Risk factors for low back pain and sciatica. Annals of Medicine, 21, 257-264. http://dx.doi.org/10.3109/07853898909149202

[31] Setton, L.A. and Chen, J. (2006) Mechanobiology of the intervertebral disc and relevance to disc degeneration. The Journal of Bone \& Joint Surgery, 88, 52-57. http://dx.doi.org/10.2106/JBJS.F.00001

[32] Adams, M.A. and Roughley, P.J. (2006) What is intervertebral disc degeneration, and what causes it? Spine, 31, 2151-2161. http://dx.doi.org/10.1097/01.brs.0000231761.73859.2c

[33] Antoniou, J., Steffen, T., Nelson, F., Winterbottom, N., Hollander, A.P., Poole, R.A., Aebi, M. and Alini, M. (1996) The human lumbar intervertebral disc: evidence for changes in the biosynthesis and denaturation of the extracellular matrix with growth, maturation, ageing, and degeneration. Journal of Clinical Investigation, 98, 9961003. http://dx.doi.org/10.1172/JCI118884

[34] Cloyd, J.M. and Elliott, D.M. (2007) Elastin content correlates with disc degeneration in the annulus fibrosus and nucleus pulposus. Spine, 32, 1826-1831. http://dx.doi.org/10.1097/BRS.0b013e3181132a9d

[35] Anderson, D.G. and Tannoury, C. (2005) Molecular pathogenic factors in symptomatic disc degeneration. The Spine Journal, 5, 260S-266S.

http://dx.doi.org/10.1016/j.spinee.2005.02.010

[36] Le Maitre, C.L., Pockert, A., Buttle, D.J., Freemont, A.J. and Hoyland, J.A. (2007) Matrix synthesis and degradation in human intervertebral disc degeneration. Biochemical Society Transactions, 35, 652-655. http://dx.doi.org/10.1042/BST0350652

[37] Orita, S., Miyagi, M., Kobori, S., Gemba, T., Ishikawa, T., Inoue, G., Toyone, T., Aoki, Y., Eguchi, Y., Takahashi, K. and Ohtori, S. (2013) IkB kinase b inhibitor downregulates pain-related neuropeptide production in the sensory neurons innervating injured lumbar intervertebral discs in the dorsal root ganglia of rats. The Spine Journal, 13, 284288. http://dx.doi.org/10.1016/j.spinee.2013.01.020

[38] Burke, J.G., Watson, R.W., McCormack, D., Dowling, F.E., Walsh, M.G. and Fitzpatrick, J.M. (2002) Intervertebral discs which cause low back pain secrete high levels of proinflammatory mediators. Journal of Bone \& Joint Surgery, 84, 196-201. http://dx.doi.org/10.1302/0301-620X.84B2.12511

[39] Urban, J.P., Smith, S. and Fairbank, J.C. (2004) Nutrition of the intervertebral disc. Spine, 29, 2700-2709. http://dx.doi.org/10.1097/01.brs.0000146499.97948.52

[40] Adams, M.A. and Roughley, P.J. (2006) What is intervertebral disc degeneration, and what causes it? Spine, 31, 2151-2161. http://dx.doi.org/10.1097/01.brs.0000231761.73859.2c

[41] Paassilta, P., Lohiniva, J., Göring, H.H., Perälä, M., Räinä, S.S., Karppinen, J., Hakala, M., Palm, T., Kröger, H., Kaitila, I., Vanharanta, H., Ott, J. and Ala-Kokko, L. (2001) 
Identification of a novel common genetic risk factor for lumbar disk disease. Journal of the American Medical Association, 285, 1843-1849. http://dx.doi.org/10.1001/jama.285.14.1843

[42] Kawaguchi, Y., Kanamori, M., Ishihara, H., Ohmori, K., Matsui, H. and Kimura, T. (2002) The association of lumbar disc disease with vitamin-D receptor gene polymerphism. Journal of Bone \& Joint Surgery, 84, 2022-2028.

[43] Kawaguchi, Y., Osada, R., Kanamori, M., Ishihara, H., Ohmori, K., Matsui, H. and Kimura, T. (1999) Association between an aggrecan gene polymorphism and lumbar disc degeneration. Spine, 24, 2456-2460. http://dx.doi.org/10.1097/00007632-199912010-00006

[44] Noponen-Hietala, N., Kyllönen, E., Männikkö, M., Ilkko, E., Karppinen, J., Ott, J. and Ala-Kokko, L. (2003) Sequence variations in the collagen IX and XI genes are associated with degenerative lumbar spinal stenosis. Annals of the Rheumatic Diseases, 62, 1208-1214. http://dx.doi.org/10.1136/ard.2003.008334

[45] Ahn, S.H., Cho, Y.W., Ahn, M.W., Jang, S.H., Sohn, Y.K. and Kim, H.S. (2002) mRNA expression of cytokines and chemokines in herniated lumbar intervertebral discs. Spine, 27, 911-917. http://dx.doi.org/10.1097/00007632-200205010-00005

[46] Lewin, G.R. and Barde, Y.A. (1996) Physiology of the neurotrophins. Annual Review of Neuroscience, 19, 289317. http://dx.doi.org/10.1146/annurev.ne.19.030196.001445

[47] Lu, B., Pang, P.T. and Woo, N.H. (2005) The yin and yang of neurotrophin action. Nature Reviews Neuroscience, 6, 603-614. http://dx.doi.org/10.1038/nrn1726

[48] Richardson, S.M., Doyle, P., Minogue, B.M., Gnanalingham, K. and Hoyland, J.A. (2009) Increased expression of matrix metalloproteinase-10. Nerve growth factor and substance $\mathrm{P}$ in the painful degenerated intervertebral disc. Arthritis Research and Therapy, 11, R126. http://dx.doi.org/10.1186/ar2793

[49] Priestley, J.V., Michael, G.J., Averill, S., Liu, M. and Willmott, N. (2002) Regulation of nociceptive neurons by nerve growth factor and glial cell line derived neurotrophic factor. Canadian Journal of Physiology and Pharmacology, 80, 495-505.

http://dx.doi.org/10.1139/y02-034

[50] Salio, C., Averill, S., Priestley, J.V. and Merighi, A. (2007) Costorage of BDNF and neuropeptides within individual dense-core vesicles in central and peripheral neurons. Developmental Neurobiology, 67, 326-338. http://dx.doi.org/10.1002/dneu.20358

[51] Freemont, A.J., Watkins, A., Le Maitre, C., Baird, P., Jeziorska, M., Knight, M.T., Ross, E.R., O’Brien, J.P. and Hoyland, J.A. (2002) Nerve growth factor expression and innervation of the painful intervertebral disc. Journal of Pathology, 197, 286-292. http://dx.doi.org/10.1002/path.1108

[52] Laplante, B.L., Ketchum, J.M., Saullo, T.R. and De Palma, M.J. (2012) Multivariable analysis of the relationship between pain referral patterns and the source of chronic low back pain. Pain Physician, 15, 171-178.

[53] Schwarzer, A.C., Aprill, C.N., Derby, R., Fortin, J., Kine,
G. and Bogduk, N. (1995) The prevalence and clinical features of internal disc disruption in patients with chronic low back pain. Spine, 20, 1878-1883. http://dx.doi.org/10.1097/00007632-199509000-00007

[54] Jensen, M.C., Brant-Zawadzki, Obuchowski, N., Modic, M.T., Malkasian, D. and Ross, J.S. (1994) Magnetic resonance imaging of the lumbar spine in people without back pain. The New England Journal of Medicine, 331, 69-73. http://dx.doi.org/10.1056/NEJM199407143310201

[55] Emch, T.M. and Modic. M.T. (2011) Imaging of lumbar degenerative disk disease: History and current state. Skeletal Radiology, 40, 1175-1189. http://dx.doi.org/10.1007/s00256-011-1163-x

[56] Modic, M.T. and Ross, J.S. (2007) Lumbar degenerative disk disease. Radiology, 245, 43-61. http://dx.doi.org/10.1148/radiol.2451051706

[57] Aoki, Y., Ohtori, S., Takahashi, K., et al. (2004) Innervation of the lumbar intervertebral disc by nerve growth factor-Dependent neurons related to inflammatory pain. Spine, 29, 1077-1081. http://dx.doi.org/10.1097/00007632-200405150-00005

[58] Bogduk, N., Aprill, C. and Derby, R. (2013) Lumbar discogenic pain: State-of-the-art review. Pain Medicine, 14, 813-836. http://dx.doi.org/10.1111/pme.12082

[59] Haughton, V. (2011) The “dehydrated” lumbar intervertebral disk on MR, its anatomy, biochemistry and biomechanics. Neuroradiology, 53, 191-194. http://dx.doi.org/10.1007/s00234-011-0923-6

[60] Pfirrman, C.W., Metzdorf, A., Zanetti, M., Hodler, J. and Boos, N. (2001) Magnetic resonance classification of lumbar intervertebra disc degeneration. Spine, 126, 18731878. http://dx.doi.org/10.1097/00007632-200109010-00011

[61] Rhame, R. and Moussa, E. (2008) The modic vertebral endplate and marrow changes pathologic significance and relation to low back pain and segmental instability of the lumbar spine. American Journal Neuroradiology, 29, 838842. http://dx.doi.org/10.3174/ajnr.A0925

[62] Kuisma, M., Karppinen, J. and Niinimaki, J. (2007) Modic changes in endplates of lumbar vertebral bodies: prevalence and association with low back and sciatic pain among middle-aged male workers. Spine, 31, 1714-1718. http://dx.doi.org/10.1097/01.brs.0000224167.18483.14

[63] Del Grande, F., Maus, T.P. and Carrino, J. (2012) Imaging the intervertebral disk, age-related changes, herniations and radicular pain. Radiologic Clinics of North America, 50, 629-649. http://dx.doi.org/10.1016/j.rcl.2012.04.014

[64] Sachs, B.L., Vanharante, H., Spivey, M.A. (1987) Dallas discogram description. A new classification of CT/Discography in low back disordes. Spine, 12, 295-298. http://dx.doi.org/10.1097/00007632-198704000-00018

[65] Boden, S.D., Davis, D.O., Dina, T.S., et al. (1990) Abnormal magnetic-resonance scans of the lumbar spine in asymptomatic subjects. A prospective investigation. Journal of Bone \& Joint Surgery, 72, 403-408.

[66] Koes, B.W., van Tulder, M.W. and Peul, W.C. (2007) Diagnosis and treatment of sciatica. British Medical Journal, 334, 1313-1317. 
http://dx.doi.org/10.1136/bmj.39223.428495.BE

[67] Luijsterburg, P.A., Verhagen, A.P., Ostelo, R.W., van den Hoogen, H.J., Peul, W.C., Avezaat, C.J. and Koes, B.W. (2008) Physical therapy plus general practitioners' care versus general practitioners' care alone for sciatica: A randomised clinical trial with a 12-month follow-up. European Spine Journal, 17, 509-517. http://dx.doi.org/10.1007/s00586-007-0569-6

[68] Buttermann, G.R. (2004) The effect of spinal steroid injections for degenerative disc disease. Spine, 4, 495-505. http://dx.doi.org/10.1016/j.spinee.2004.03.024

[69] Saal, J.A. and Saal, J.S. (2000) Intradiscal electrothermal treatment for chronic discogenic low back pain: A prospective outcome study with minimum 1-year follow-up.
Spine, 25, 2622-2627. http://dx.doi.org/10.1097/00007632-200010150-00013

[70] Kapural, L., Mekhail, N., Hicks, D., Kapural, M., Sloan, S., Moghal, N., Ross, J. and Petrinec, D. (2008) Histological changes and temperature distribution studies of a novel bipolar radiofrequency heating system in degenerated and nondegenerated human cadaver lumbar discs. Pain Medicine, 9, 68-75. http://dx.doi.org/10.1111/j.1526-4637.2007.00410.x

[71] Winn, H.R., Bullock, M., Hovda, D., Schouten, J., Maas, A., Frank, L.A. and Christopher, P.A. (2011) Youmans neurological surgery: Chapter 273-Diagnosis and management of diskogenic lower back pain. Vol. 3, Elsevier Saunders, Philadelphia. 